\title{
Identification of Heuristics for Assessing the Usability of Websites of Public Administration Units
}

\author{
Łukasz Krawiec, Helena Dudycz \\ Wrocław University of Economics, Wroclaw, Poland \\ Email: \{lukasz.krawiec, helena.dudycz\}@ue.wroc.pl
}

\begin{abstract}
A very important aspect of modern websites is their usability. Thanks to modern, and constantly developing technologies it is possible to create user-friendly services for each user. The usefulness of online services may be considered in terms of their functionality, clarity, and accessibility. It is particularly important that these criteria are met by public administration websites. The aim of this paper is to present the most common usability errors identified on the websites of public administration units as well as to indicate the links between particular types of problems and traditional heuristics of Jakob Nielsen. The survey was conducted by evaluating the websites of the Public Information Bulletin in Poland (BIP, which stands for "Biuletyn Informacji Publicznej"), which are supposed to provide universal access to public information by the citizens of the country. A heuristic method (based on J. Nielsen's heuristics) was used to evaluate 60 websites. The errors obtained were grouped into 14 categories. Each of the error groups was assessed by an expert in terms of its importance for the overall assessment of the website's usefulness. The analysis of relations between the identified categories of errors and heuristics of Jakob Nielsen indicates a need for specifying heuristics in the context of evaluating the usability and availability of public administration websites.
\end{abstract}

\section{INTRODUCTION}

$\mathrm{R}$ egardless of the motives of designers or clients - the purpose of websites mainly comes down to the effective presentation of their content and efficient conveyance of information (usefulness) to the largest possible audience (accessibility). This means that it is important to ensure that both healthy and disabled people are able to effectively familiarise themselves with the information provided on the website and take advantage of its functionalities.

As far as creating useful and accessible websites of public administration units is concerned, it is necessary to conduct continuous research and usability tests, perceiving it as one of the basic activities in the process of developing such websites. The aim of such activities is to prevent dissatisfaction among users (i.e. citizens) and to provide a place where they can find the information they need quickly and efficiently.

The aim of this paper is to categorise the most common errors identified on the websites of public administration units as well as to indicate the links between particular types of problems and traditional heuristics of Jakob Nielsen. This will help adjust the heuristic method to the needs of further usability studies of this kind of websites.

The structure of the paper is outlined below. The next section briefly explains the concept of usability in the context of websites. The section that follows focuses on the characteristics of the heuristic method for testing and evaluation of usefulness. Next, the Polish Public Information Bulletin is briefly described. The penultimate section presents the proposed procedure for the examination and the results obtained. Finally, a summary of the paper is provided.

\section{THE USEFULNESS OF A WEBSITE}

In literature, usability is defined in a variety of ways. According to ISO 9241 [1], usability defines "the extent to which a system, product or service can be used by specified users to achieve specified goals with effectiveness, efficiency and satisfaction in a specified context of use", while the standard ISO / IEC 9126-1 (for Standardization and Commission, 2001), related to Software Engineering and product quality, describes usability as the ability of the software product to be understood, its operation learned, to be operated, and to be attractive to the user. In the literature, usability is defined as the "capacity to be used" the device [2] and depends on what the user wants to do [3].

According to J. Nielsen, usability "is a quality attribute that assesses how easy user interfaces are to use" [4], comprising 5 components:

- Learnability: How easy is it for users to accomplish basic tasks the first time they encounter the design?

- Efficiency: Once users have learned the design, how quickly can they perform tasks?

- Memorability: When users return to the design after a period of not using it, how easily can they re-establish proficiency?

- Errors: How many errors do users make, how severe are these errors, and how easily can they recover from the errors?

- Satisfaction: How pleasant is it to use the design? [4].

The studies described in the literature [5] indicate that usability is the most important parameter affecting the quality of websites evaluated by their users. According to Paplauskaite [6], the usability of the website determines its legibility, intuitiveness, and comfort of use. The concept 
of web usability is connected with the concept of web accessibility. It means that people with disabilities have full access to the content of a given website, can understand it as well as benefiting from convenient navigation and interaction with the website [7]. It can, therefore, be concluded that the accessibility of websites is related to the human-computer interaction and is a feature of the user interface that allows all people to use it, regardless of their hardware, software or disability. Accessibility problems are most common among users with reduced mobility, hearing or vision, including those with cognitive disorders [8, p. 41; 9, p. 169]. Accessibility is now seen more broadly, i.e. the aim is to make the website accessible to as many people as possible, including the elderly, people with disabilities, people with low bandwidth internet access, and people using older devices, which are usually slower than modern ones [10].

P. Morville names usability and accessibility as two separate dimensions out of the six that make up User Experience, altogether creating a profit or value for the user, ensuring that they receive a product that meets their needs [11]. According to other authors, usability is a broader concept, a subset of which is accessibility, including issues such as interface handling problems experienced by people with disabilities [12, p. $7 ; 13]$.

\section{THE HEURISTIC METHOD APPLIED FOR EXAMINING WEBSITES}

The literature discusses many ways to study the usefulness of websites $[2 ; 14-18]$. One of them is the heuristic method, which is one of the expert, inspection-based techniques of recognising usability problems. It consists in indicating the extent to which a given piece of software or a website complies with the developed rules and standards (called usability heuristics [2]) for the design of human-computer interactions. In this method, experts indicate what is correct and what is incorrect about the website being evaluated in terms of the heuristics applied [19].

The heuristic analysis of a website is a universal and easily applicable method. It is used for researching entire websites, as well as only one or two pages of a given website. It is a relatively inexpensive method as there is no need to involve users and the indicated number of experts is limited, i.e. three to eight experts are considered to be the optimal number [20]. An independent analysis performed by each of them supports the study's objectivity of and effectiveness. Thanks to this method, it is possible to detect many small as well as major errors related to the website's performance. Also, it allows one to identify the elements of the website that may adversely affect its usability.

The literature most often refers to heuristics developed by $\mathrm{J}$. Nielsen, also referred to as traditional ones. These are [4]:

H01. Visibility of system status The purpose of the system is to inform the user about what is currently happening while working with the system, e.g. by sending a message in situations where the system's response time is longer than usual or by placing very helpful progress bars while the user is performing a process consisting of several steps. Sounds or backlighting can be also applied to enhance feedback.

H02. Correspondence between the system and the real world The system should avoid technical terms and use only terms and expressions known to the user. In addition, the system should present only the information that is actually needed by the user. It is recommended that it be naturally and logically ordered.

H03. User control and freedom The result of the user's actions within the system should be reversible. It often happens that a person using a certain solution mistakenly chooses an option other than the desired one. In such a situation, the system is required to be able to revert activities without having to go through successive stages of the process with an incorrectly selected variant or repeat all the steps from scratch. A well-designed system should allow the user to pause their activities at any time and resume in the same place after the interruption.

H04. Consistency and standards The system should be consistent visually (the appearance of windows, colours, the layout of buttons, etc.), operationally (same way of starting operations, same keyboard shortcuts, etc.), and behaviourally (the system's expected reaction to the user's actions). The person using the product should have no doubt about whether similar phrases or actions always mean the same. It is recommended that the conventions applied to the whole platform be adhered to.

H05. Prevention of errors It is recommended that situations in which human error is likely should be detected and removed. As for uncertain situations, the system should ask the user if they are sure whether they want to execute the command. It is also worth using various forms of facilitation that will effectively eliminate common errors, for example, by checking spelling, grammar, or command line correctness.

H06. Recognition and not remembering The system should not require the user to remember information between successive stages of the dialogue. Access to information relating to the operation of the system should be possible from any location. In addition, it is important to ensure that all available options and actions are clearly visible.

H07. Flexibility and efficiency of use A desirable feature of a good system is that it allows operation using shortcuts. Activities often performed by the user should be flexible and adaptable to their needs. It is recommended that keyboard shortcuts, auto-supplements, lists of recently used commands, quick access bars, etc. be used. For tedious, multi-step processes, the system should allow the user to create macro commands.

H08. Aesthetic and minimalist design It is recommended to avoid placing unnecessary and distracting elements in the dialogue. They reduce the focus of the person using the solution on the proper content of the task. It should also 
be remembered that simple designs, with a small number of elements, indicate the system's ease of use.

H09. Help users recognise, diagnose, and recover from errors Error messages sent by the system should be written in a language that is easy for the user to understand. They should carefully explain the cause of the error and suggest a way to repair it.

H10. Help and documentation It is recommended that every system have access to a user manual that should not be too extensive. The user, using this type of manual, should be able to easily find the information they need. Welldesigned manuals describe the steps the user needs to take to restore their system back to normal.

In addition to the heuristics described above, the literature provides many other approaches to evaluating usefulness with this method, including the following:

- Cognitive Engineering Principles for Enhancing HumanComputer Performance [21],

- Weinschenk and Barker classification [22],

- The Eight Golden Rules of Interface Design [23],

- Usability Heuristics for Touchscreen-based Mobile Devices [24],

- First Principles of Interaction Design [25],

- 7 Usability Heuristics That All UI Designers Should Know [26].

Many of the above rules and guidelines are based on J. Nielsen's classic heuristics. The aim of many heuristics creators is to update and match them to the study of specific IT systems [27-28]. New heuristics proposals also result from a change in the way of looking at the interface usability issue. For example, the aforementioned Gerhardt-Powals [21] takes a more holistic approach to evaluation, including principles such as: automate unwanted workload, group data in consistently meaningful ways, practice judicious redundancy. A more detailed and fragmented approach is proposed by Susan Weinschenk and Dean Barker [22] on their list of twenty guidelines. These are among others: user control, accommodation, simplicity or predictability. Ben Shneiderman's goal was to create flexible principles that can be adapted to interfaces in different programming environments. For example: strive for consistency, seek universal usability, permit easy reversal of actions [23]. A similar point of view is represented by Bruce Tognazzini's guidelines, such as: aesthetic design, anticipation, autonomy, discoverability [25]. Most interface usability experts follow similar principles or build on existing proposals.

\section{THE PUBLIC INFORMATION BULLETIN AS AN EXAMPLE OF A PUBLIC ADMINISTRATION WEBSITE}

From the perspective of the public interest, especially in the age of the information society, all public administration websites should offer features such as usability, or accessibility, which is inherent in it. The most important and widespread standard for this feature in the world is the WCAG (Web Content Accessibility Guidelines). Many countries are implementing additional recommendations and legal requirements to ensure the quality of public websites containing information and content of particular interest to the general public. Among the examples thereof are the US Section 508 of the Workforce Rehabilitation Act [29], the German Barrierefreie-Informationstechnik-Verordnung [30], or the Italian Stanca Act [31], adjusting the law to the W3C WCAG 2.0 accessibility requirements.

In Poland, the Public Information Bulletin (BIP) is an example of a website of public administration units, constituting a unified system of Internet services ensuring free-of-charge and universal access to public information in Poland. Apart from the main website of the Public Information Bulletin (https://bip.gov.pl), the bulletin consists of services provided by entities obliged to maintain them, such as public authorities, economic and professional selfgovernment bodies, entities representing state organisational units, political parties, and many others. Their task is to inform the public about their activity, i.e. to make public information available. Additionally, detailed requirements and recommendations for BIP administrators can be found on the website of the Ministry of Digitisation (https://bip.gov.pl). The straight majority of the above quality requirements come down to the concept of usability. BIP websites should, therefore, be exemplary in terms of this requirement in the context of heuristics adopted both as guidelines for the development of websites, as well as those used for research and evaluation of their usefulness using the heuristic method.

BIP websites are always marked with the appropriate logotype. Although a BIP website is linked to the authorities of a given city, it is a separate website and differs from the website of the city's administration unit. Given that, administrators of the respective types of websites (i.e. BIP and city administration, such as https://www.wroclaw.pl and http://bip.um.wroc.pl), often cooperate by providing hyperlinks to each other's websites or by distributing content according to its function. In some cases, both websites are placed next to each other, i.e. on the same server, but being two different and separate projects.

\section{RESEARCH METHODOLOGY}

\section{A. Procedure}

In order to identify heuristics relevant for the assessment of the usefulness of websites of public administration units, a study was conducted to assess the usefulness of selected 60 websites of the Public Information Bulletin. The examination was performed according to the following procedure:

1. Selecting the Public Information Bulletin websites for research purposes.

2. Researching the websites of the Public Information Bulletin using J. Nielsen's heuristics.

3. Identification of basic errors related to the usability of the Public Information Bulletin websites examined.

4. Categorisation of usability errors. 
5. Evaluation of the importance and ranking of the different categories of errors.

6. Comparison of the proposed categories of errors with J. Nielsen's heuristics. below.

The results of the study are presented in the paragraphs

\section{B. Identification of basic errors related to the usability of the Public Information Bulletin websites examined}

The research began with an analysis of sixty websites of the Public Information Bulletin of large Polish cities. The research was conducted by 120 students aged 23-40, during classes in the subject of "usability of the human-computer interface". These people have been trained to do this task. Students worked in two-person groups, each researched one website. The test results were then verified by an expert. The website evaluation procedure was based on Nielsen's heuristics. After determining the general state of the usefulness of websites of this type, the research was narrowed down to twenty largest cities in terms of population (the most up-to-date data from the Central Statistical Office, i.e. from 31.12.2015 were used [32]). This time the analysis was more in-depth due to the fact that it included accessibility aspects. A number of errors and violations were thus identified, which had a material impact on the usability assessment. At a later stage, those had to be classified. A detailed analysis allowed us to identify the areas of the most frequently occurring errors and problems. Fourteen categories of errors were formulated:

F01. Website ergonomics: non-intuitive and unusual location of the website's key elements (e.g. main menu, search fields, accessibility functions, etc.) and too large and unstructured accumulation of elements on the main page, including many unnecessary ones.

F02. Website consistency: the selective appearance of key elements that should appear on each page within the website (e.g. main menu, footer, search field, etc.).

F03. Content and its form: errors in the text (spelling, punctuation, etc.), incorrect encoding of diacritical marks, illegible and inconsistent formatting and arrangement of the text (typefaces, colours, boldening, indentations, spaces, etc.), too few or too many graphic elements (including photographs) affecting the quality of the visitor's website experience, non-standard or user-unfriendly content presentation, and frequent replacement of content with external attachments (e.g. as PDF files).

F04. Substantive content: outdated or incomplete information, inconsistency of the information presented within pages belonging to a single category (e.g. selective contact details for individual departments of the city council - telephone and fax numbers provided for some of them and only an e-mail address provided for others), use of a specialist (legal or technical vocabulary) or convoluted (multiply compound sentences, etc.) language.

F05. Navigation, menus, and grouping of web pages: too many or too few options in the main or auxiliary menu (the problem of a proper number of nests), non-intuitive arrangement and illegible presentation of options, lack of clear information about the possibility of rolling down submenus, recurring menu panels across one page, inconsistencies of individual instances of the website's main or auxiliary menu.

F06. Navigation between web pages: lack of or errors in breadcrumb navigation, poorly visible navigation panel, inconsistently performing links, lack of return to parent location button, lack of redirection to the homepage after pressing the logotype or title.

F07. Navigation - website search engine: performance errors, lack of results, unconventional format of results (e.g. official documents only), lack or a small number of advanced search options (filtering), lack of hints when entering text.

F08. Navigation - links: incorrectly described (alternative text) and outdated hyperlinks, references to non-existent locations, lack of description of error 404, lack of information about redirecting to an external website, lack of options for opening new pages in a new tab or in a new window.

F09. Accessibility - mobile devices: lack of website responsiveness, incorrectly executed mobile version of the website, problems with scaling individual elements (e.g. search fields).

F10. Accessibility - colour set: aesthetically unpleasant shades of colours and their saturation, too big or too small variety of colours, too big or too small contrasts.

F11. Accessibility - functions: illegible text, incorrect performance or lack of buttons related to accessibility (e.g. text scaling, changing contrast, etc.).

F12. Accessibility - website map: lack of or incorrectly designed, illegible website map.

F13. Help: hardly exhaustive or even non-existent help section, errors in the help section (problems which also concern the frequently asked questions), lack of hints and messages in problematic areas of the website.

F14. Other errors and limitations: the website loading time is too long or the loading process is completely stopped often without any messages, access to all functionalities of the website is possible only after registration.

By means of expert analysis, each category of errors was rated in terms of its importance for the overall evaluated of the service's usefulness. The highest ranks were assigned to the categories that determine the possibility of using the website's functionalities, while the lowest ones reflect problems causing only users' moderate discomfort. The scale of the ranks is as follows:

1 - a problem of least significance;

2 - a minor problem;

3 - a problem of average significance;

4 - a major error;

5 - a critical error. 
Each of the identified error areas was assigned one of five ranks. The results of this study are presented in table 1 .

TABLE 1

RANKS OF ERROR CATEGORIES

\begin{tabular}{|c|l|c|}
\hline No. & Error categories & Rank \\
\hline F01 & Website ergonomics & 2 \\
\hline F02 & Consistency across the website & 2 \\
\hline F03 & Content and the form of content presentation & 3 \\
\hline F04 & Content and the substantive matter & 3 \\
\hline F05 & Navigation, menu, and page grouping & 5 \\
\hline F06 & Navigation between web pages & 5 \\
\hline F07 & Navigation - website search engine & 4 \\
\hline F08 & Navigation - links & 5 \\
\hline F09 & Accessibility - mobile devices & 4 \\
\hline F10 & Accessibility - colour set & 3 \\
\hline F11 & Accessibility - functions & 5 \\
\hline F12 & Accessibility - website map & 1 \\
\hline F13 & Help & 1 \\
\hline F14 & Other error and hindrances & 3 \\
\hline
\end{tabular}

The most serious problems (rank 5 and 4) found across the BIP websites under examination are navigation difficulties (F05-F08) and availability limitations (F09 and F11). Violations such as F05-F08 i.e. ones related to website navigation can make it completely impossible to find the information needed by the user. During testing, in many cases, the unintuitive menu layout, containing an enormous number of mixed and unnecessary options, combined with an unoperational search engine, made it impossible to find the searched content.

The second type of serious error concerns availability. An increasing number of people are using smartphones and tablets, more and more often abandoning desktop computers. The lack of possibility to use a mobile device or limitations in this respect may effectively discourage many Internet users. Also the lack of accessibility-related functions (e.g. change of contrast) means a serious barrier for people with medical conditions, thus striking the basic principles and sense of BIP websites. The importance of colour choices (F10) has been rated as slightly lesser (average rank, i.e. 3) as it is solved by the contrast matching option mentioned above. Moreover, in none of the cases analysed did the colour scheme pose a considerable problem when reading the content. The same rank was assigned to F03 and F04. These are important aspects of a website, but rather than preventing its use they result in the user's impatience and irritation. The last area, F14, was also given an average rating, due to the diversity and occasionality of errors. The first two categories are less important for the perception of the website and are associated with bad user experience rather than serious impairment of usability, therefore they were assigned a lower rank of 2. The least important are areas F12 and F13, which should be only a supplement to a well-developed website.
C. Comparison of the identified categories of errors with J. Nielsen's heuristics

The errors identified across the BIP websites, described in the previous section (i.e. F01-F14), were assigned to Jakob Nielsen's ten heuristics (specified in section 3). Table 2 presents a breakdown of the identified error areas and Nielsen's heuristics.

Every link between an error category and a heuristic is marked with an "X". One error area can be associated with several heuristics, while one heuristic can cover several of the specified problem categories. The last column and last row of the table summarise the number of links. For example, category F05 is thematically linked with almost all heuristics (from $\mathrm{H} 01$ to H08). Hence, the sum at the end of the line (last column) is 8 . This category, therefore, affects many aspects of the site. The table can also be read from the perspective of heuristics. For example, H09 will only be affected in four error categories (F08, F11, F13, F14).

$\mathrm{H} 03-\mathrm{H} 05$ and $\mathrm{H} 07$ are the most frequently violated heuristics, i.e. those linked with the highest number of errors. These relate to the user's control over navigation, maintaining consistency and standards, error prevention, as well as errors that affect the effectiveness of use. These are therefore heuristics concerning the most serious usability violations. As for the error areas that concern the greatest number of heuristics, these are as follows: F05, F08, and F11, i.e. again navigation and availability and the less important element of B13 (help).

It turns out that the most serious errors are also the most common ones: F05-F08 (navigation, menu, control, search engine, and links) and F11 (accessibility functions). Individual usability violations covered by these areas appeared in at least half of the websites examined.

\section{CONCLUSIONS AND FUTURE WORKS}

This paper presents identified categories of errors occurring on public administration websites, which were associated with traditional heuristics of Jakob Nielsen. The proposed categories may be heuristics to be applied under the heuristic method for assessing the usefulness of websites. Compared to J. Nielsen's heuristics, in the identified categories of errors, many refer to website accessibility. Meeting the requirements for website accessibility is ensured by features such as the clarity and intuitiveness of the website, which translates into a good reception of the website by both healthy and disabled people. This means that the greater accessibility of the website improves usability as perceived by all users. Therefore, when testing the usability of a website, it is necessary to pay more attention to the verification of its availability.

Identification of the most frequent errors and usability violations on the websites of public administration units as well as determining their correlation with Jakob Nielsen's heuristics will be the basis for further research in this area. Its aim is to develop a comprehensive procedure for testing the usability and availability of public administration 
services, with expert analysis being an element of key importance. Tests using this procedure will be conducted on the websites of the Public Information Bulletin. Further work may also result in the presentation of a modified version of Nielsen's classic heuristics, tailored to the needs of testing public websites. The research is needed especially in view of those at risk of digital exclusion, as well as in view of the rapid growth of the Internet.

TABLE 2.

HEURISTICS VIOLATIONS

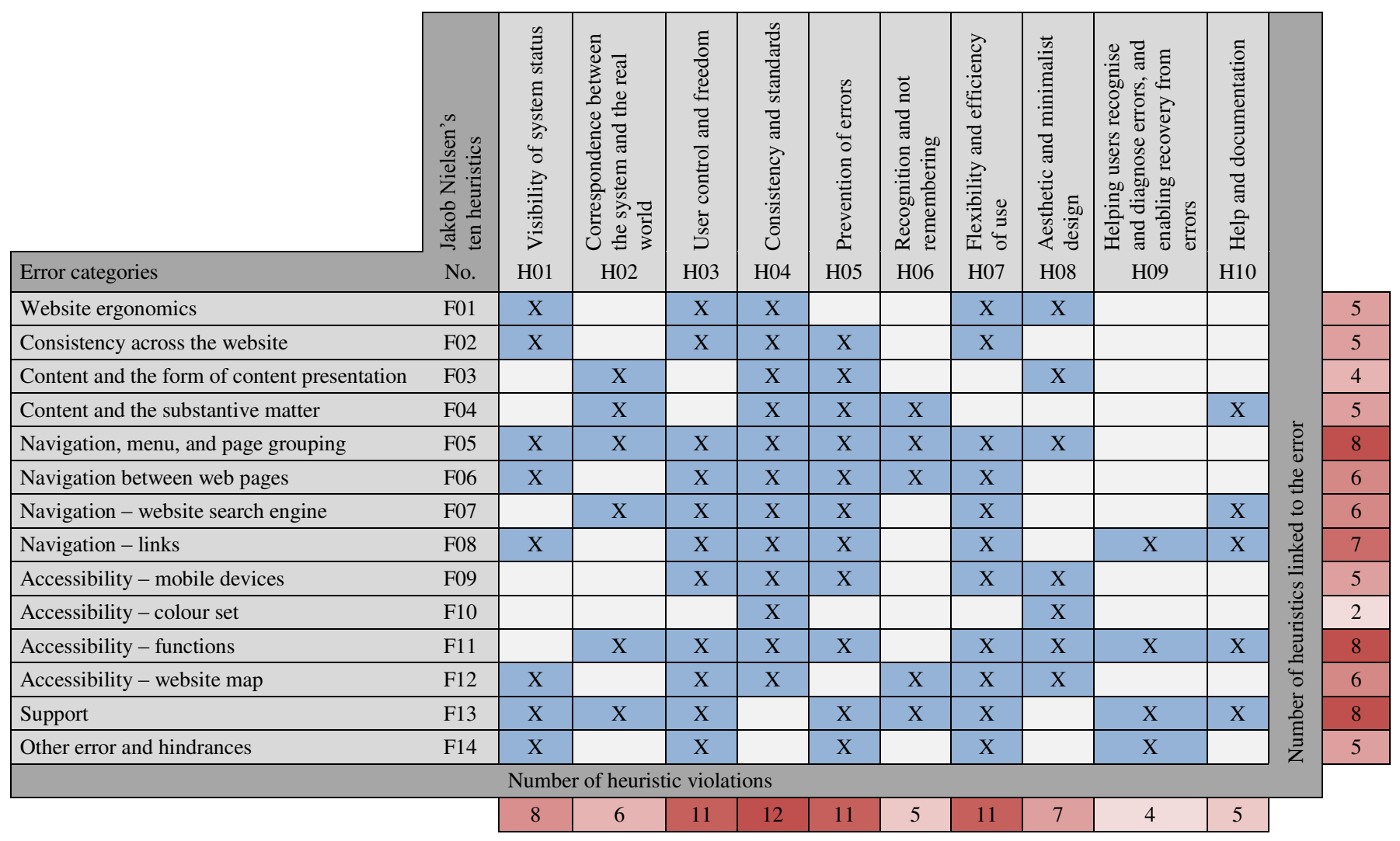

\section{REFERENCES}

[1] ISO 9241-210: 2010. Ergonomics of human-system interaction - Part 210: Human-centred design for interactive systems. https://www.iso.org/obp/ui/\#iso:std:iso:9241:-210:ed1:v1:en:en,\%20dostęp\%20dnia\%2013.05.2016 (12.01.2018).

[2] Qui nones, D., Rusu, C., 2017. How to develop usability heuristics: A systematic literature review. Computer Standards \& Interfaces, vol. 53, pp. 89-122. doi: 10.1016/j.csi.2017.03.009.

[3] Inostroza, R., Rusu, C., Roncagliolo, S., Rusu, V., Collazos, C. A., 2016. Developing SMASH: A set of smartphone's usability heuristics. Computer Standards \& Interfaces, 43, pp. 40-52.

[4] Nielsen, J., 2012. Usability 101: Introduction to Usability. https://www.nngroup.com/articles/usability-101-introduction-tousability (29.10.2018).

[5] Khalid H., Hedge A., Ahram T., Advances in Ergonomics Modeling and Usability Evaluation, CRC Press 2011.

[6] Paplauskaite, L., 2014. Usability and usufulness in UX Web Design. https://bitzesty.com/2014/05/15/usability-and-usefulness-in-ux-webdesign (20.07.2018).

[7] Lawton Henry, S., 2019. Introduction to Web Accessibility. https://www.w3.org/WAI/fundamentals/accessibility-intro (1.05.2019).

[8] Robbins, J. N., 2014. Projektowanie stron internetowych, Przewodnik dla początkujących webmasterów po HTML5, CSS3 i grafice. Wydawnictwo Helion, Gliwice

[9] Phyo, A., 2003. Web Design, Projektowanie atrakcyjnych stron WWW. Wydawnictwo Helion, Gliwice.

[10] Streich, S., Accessibility is NOT just for people with disabilities. https://vimm.com/website-accessibility (1.05.2019).
[11] Morville, P., 2004. User Experience Design. http://semanticstudios.com/user_experience_design (20.07.2018).

[12] Waddell, C., Regan, B., Lawton Henry, S., Burks, M. R., Thatcher, J., Urban, M. D., Bohman, P., 2002. Constructing Accessible Web Sites. Apress Publishing House.

[13] Lawton Henry, S., Abou-Zahra, S., White, K., 2016. Accessibility, Usability, and Inclusion. https://www.w3.org/WAI /fundamentals/accessibility-usability-inclusion (1.05.2019).

[14] Fernandez, A., Insfran, E., Abrahão, S., 2011. Usability evaluation methods for the web: A systematic mapping study, Information and Software Technology, vol. 53, Issue 8, pp. 789-817. doi.org/10.1016/j.infsof.2011.02.007.

[15] Lazar, J., Feng, J. H., Hochheiser, H., 2010. Research Methods in Human-computer Interaction. John Wiley \& Sons.

[16] Paz, F., Pow-Sang, J. A., 2016. A Systematic Mapping Review of Usability Evaluation Methods for Software Development Process. International Journal of Software Engineering and Its Applications, Vol. 10, No. 1 (2016), pp. 165-178. doi: 10.14257/ijseia.2016.10.1.16.

[17] Sikorski, M., 2012. User-system Interaction Design in IT Projects. Gdańsk University of Technology.

[18] Tullis, T., Albert, B., 2008. Measuring the User Experience. Collecting, Analyzing, and Presenting Usability Metrics. Morgan Kaufmann Publishers, Amsterdam.

[19] Scholtz, J., 2004. Usability evaluation. http://notification.etisalat.com.eg/etisalat/templates.backup.16082011/ 582/Usability\%2520Evaluation_rev1\%5B1\%5D.pdf.

[20] Philips, M., 2017. Elevate Your UX with a Heuristic Analysis - How to Run a Usability Evaluation, https://www.linkedin.com /pulse/elevate-your-ux-heuristic-analysis-how-run-miklos-philips (15.09.2018). 
[21] Gerhardt-Powals, J., 1996. Cognitive engineering principles for enhancing human-computer performance. International Journal of Human-Computer Interaction. Volume 8 Issue 2, April-June 1996, pp. 189-211.

[22] Weinschenk, S., Barker, D. T., 2000. Designing Effective Speech Interfaces. Wiley.

[23] Shneiderman, B., 2006. The Eight Golden Rules of Interface Design. Designing the User Interface. 6th Edition, Section 3.3.4.

[24] Inostroza, R., Rusu, C., Roncagliolo, S., Jimenez, C., Rusu, V., 2012. Usability Heuristics for Touchscreen-based Mobile Devices. IEEE Xplore, DOI: 10.1109/ITNG.2012.134.

[25] Tognazzini, B., 2014. First Principles of Interaction Design (Revised \& Expanded). askTog. https://asktog.com/atc/principles-of-interactiondesign (9.05.2019).

[26] Douglas, S., 2017. 7 Usability Heuristics That All UI Designers Should Know. Usability Geek. https://usabilitygeek.com/usabilityheuristics-ui-designers-know (19.01.2019).

[27] Jimenez, C., Lozada, P., Rosas, P., 2016. Usability heuristics: A systematic review. In: 11th Colombian Computing Conference,
27-30.09.2016, Popayan, Colombia, doi: 10.1109/ColumbianCC. 2016.7750805 .

[28] Dourado, M. A. D., Canedo E. D., 2018. Usability Heuristics for Mobile Applications - A Systematic Review. In: In Proceedings of the 20th International Conference on Enterprise Information Systems (ICEIS'2018), vol. 2, pp. 483-494 doi:10.5220/0006781404830494.

[29] Section 508 of the Rehabilitation Act. - 29 U.S.C. $\$ 798$. Section 508 Electronic and Information Technology. https://www.fcc.gov/general/section-508-rehabilitation-act (20.02.2019)

[30] Barrierefreie Informationstechnik-Verordnung - BITV 2.0. https://www.barrierefreies-webdesign.de/bitv/bitv-2.0.html (20.02.2019)

[31] Accessibilità siti web. AgID promuove l'accessibilità dei siti web in relazione alla normativa vigente. https://www.agid.gov.it/it/designservizi/accessibilita-siti-web (20.02.2019)

[32] Miasta największe pod względem liczby ludności. Główny Urząd Statystyczny. https://stat.gov.pl/statystyka-regionalna/rankingi-statystyczne/ miasta-najwieksze-pod-wzgledem-liczby-ludnosci (1.02.2019) 